\title{
A ausência de projeto urbano nas obras de mobilidade no Rio de Janeiro
}

\author{
Manuel Herce \\ Universidade Politécnica da Catalunha, Espanha \\ Contato: mhercev@gmail.com
}

As obras realizadas com motivo dos Jogos Olímpicos de 2016 constituem um bom fato para refletir sobre urbanismo, projetos urbanos e construção do espaço público da cidade.

Deixo claro, de início, que a crítica construtiva contida neste escrito não se estende às decisões do tipo de obra ou a locação delas. Mesmo achando absurda a aposta pela expansão da cidade até o final da Barra, que consolida um continuado processo nesse sentido, entendo que as decisóes de locação das instalações olímpicas correspondem à prefeitura e respeitam o que foi oferecido no dossiê da candidatura olímpica.

A principal crítica a ser realizada se refere ao fato de que essas obras, cujo custo total foi enorme, pouco ajudaram a resolver os problemas urbanísticos da cidade e, sobretudo, dos lugares onde foram construídas. E será assim porque as obras foram concebidas pensando no seu objeto principal, o transporte, e não nos requerimentos dos lugares que atravessam, dos espaços urbanos construídos, mesmo sem ter consciência desse fato.

As cidades têm, ao longo da sua história, momentos críticos nos quais um salto de patamar importante é produzido. São momentos especiais, que só se estabelecem com cadência aproximada de cada meio século, nos quais se concentram investimentos públicos enormes que as transforma e marca as regras do seu crescimento por décadas.

Assim, no caso de Rio moderno, foi paradigmática a atuação do primeiro Governo Republicano, construindo a sua moderna capital com a reforma do Centro, a construção do Porto e as concessôes de bondes e ferrovias, que marcaram a expansão da cidade e as obras infraestruturais da Light.

Outro momento de grandes investimentos na cidade se deu nos anos 1960 e 1970, quando o governador Lacerda iniciou a política de consolidação do Estado de Guanabara, com o encargo do Plano Doxiadis e a criação da Secretaria Estadual de Obras, que aprovou o Plano Quinquenal de Vias do Estado, que a ditadura militar adotou como modelo de cidade, integrando os investimentos na estratégia do GEIPIT (Grupo Espacial de Integração das Políticas de Transporte). Os investimentos, especialmente rodoviaristas, da época da ditadura, marcaram o desenvolvimento da cidade por décadas: autoestrada Lagoa-Barra (1971), Ponte de Niterói (1974), Túnel Rebouças (1969), Elevado Perimetral do Porto (1971), viadutos da Praça da Bandeira (1972) Elevado Freyssinet na Avenida Paulo de Frontin (1978), Túnel Zuzu Angel (1971) e início da Linha Vermelha (inaugurada em 1984). Também se construiu o primeiro trecho do metrô (1979) e o 
calçadão de Copacabana (1970). Da época, são o Plano de Lúcio Costa para a Baixada de Jacarepaguá (1969) e o PUB-Rio (1977).

É com o breve parêntesis do governo municipal de Maia-Conde que se chega ao momento atual, mas não é comparável ao volume de investimentos realizados recentemente, com o pretexto dos acontecimentos olímpicos. Possivelmente nunca, na história da cidade, os Governos federal, estadual e municipal tenham abordado um nível análogo de investimento. Embora na época citada tenham sido realizadas as emblemáticas obras de RioCidade, Favela-Bairro, construída a Linha Amarela, privatizada, estendida e melhorada a rede de Metrô, e completadas as obras do Rio Orla, o investimento total não alcançou a quinta parte do investimento do período pré-olímpico.

Este enorme investimento deveria ter sido realizado com um enorme capricho sobre a cidade. $\mathrm{O}$ setor público construiu o espaço público da cidade, o que perdurará por décadas e cuja principal característica é ter uma via muito mais comprida do que o espaço privatizado, que muda constantemente pela facilidade de renovar a edificação e mudar as atividades. Mas, pelo contrário, assim como o espaço privado é objeto de projetos caprichados, analisados pela prefeitura antes da aprovaçáo e difundidos nas revistas especializadas, o espaço público parece não precisar de projeto urbano.

$\mathrm{Na}$ realidade, o que acontece na cidade é a exacerbação de um modo de fazer do setor público no país, produto da conjunção de vários fatos, que se resumem em:

10) municípios com orçamentos muito magros (não tanto o do Município do Rio), táo escassos que apenas dáo para a despesa ordinária em funcionários, educação, guarda municipal, limpeza e saúde - suas responsabilidades principais;

$\left.2^{\circ}\right)$ consequente concentração da capacidade de investimento nos governos estadual e federal, cujas visóes das obras desprezam o espaço urbano;

$\left.3^{\circ}\right)$ esses fatos terminam por marcar uma pauta: só se investe em obras de grande porte, porque são aquelas que esses governos entendem que são da sua competência;

$\left.4^{\circ}\right)$ como esses organismos são mais permeáveis às influências dos grandes grupos de empreiteiros, acaba por serem esses os que decidem como se investe e em quais obras;

50) A parceria público-privada é a formula encontrada para as obras de construção de cidade. O problema reside no fato de que é uma parceria desigual, porque a parte privada decide o que construir, as soluçôes formais, a qualidade e o custo, de modo que, finalmente, consegue com a sua estratégia econômica disfarçar o balanço orçamentário e que a parte pública financie a totalidade do custo.

Com o aparente objetivo de acelerar as obras programadas para a Copa do Mundo de futebol, esquivando-se da complexa burocracia de licitaçôes, foi aprovado o Regime Diferenciado de Contratação, abjudicando-se obras apenas com um anteprojeto básico que, muitas vezes, era simplesmente um rascunho traçado sobre um mapa da Google acompanhado de um vídeo, como fotomontagem promocional. Com isso, definiamse os custos, deixando a qualidade e as decisóes de projeto nas mãos do empreiteiro.

Nem se conseguiu acelerar as obras, nem custos menores. Mas a falta de projeto prévio trouxe a destruição de muitos espaços urbanos, o desaproveitamento das externalidades da obra e uma roubalheira generalizada que deixou o país paralisado. Devia parecer táo eficaz o método, que se expandiu aos projetos do PAC, às obras olímpicas e a muitos outros investimentos. Finalmente, a Presidência da República aprovou a Medida Provisória 678, que acabou por entregar o público nas mãos das empreiteiras privadas; um velho sonho 
delas, que receberam a medida como prêmio à "discrição" mostrada nos escandalosos processos judiciais.

O Rio de Janeiro já sabe disso; porém, muitas das obras olímpicas tiveram projeto, alguns adjudicados por concurso público de profissionais. Mas quando se observam as realizaçóes, nota-se demais o protagonismo dos técnicos da empreiteira correspondente, alterando soluçóes, qualidade e preços, para desespero dos impotentes funcionários fiscalizadores.

A realidade, denunciada por poucos e, timidamente, é que o enorme investimento público feito com motivo dos Jogos Olímpicos foi uma grande oportunidade perdida, sobretudo desde a perspectiva da construçáo do espaço público da cidade, o autêntico legado que era de se esperar.

Vamos exemplificar tudo isso na construção dos corredores de transporte público.

\section{Os projetos dos corredores BRT}

Resulta em um paradoxo que o novo paradigma da mobilidade sustentável, que permitiu uma melhoria importante do espaço público das cidades europeias, esteja sendo usado não só no Brasil, como também em muitos países da Ásia e da América Latina, para criar ruas ainda menos atrativas do que as
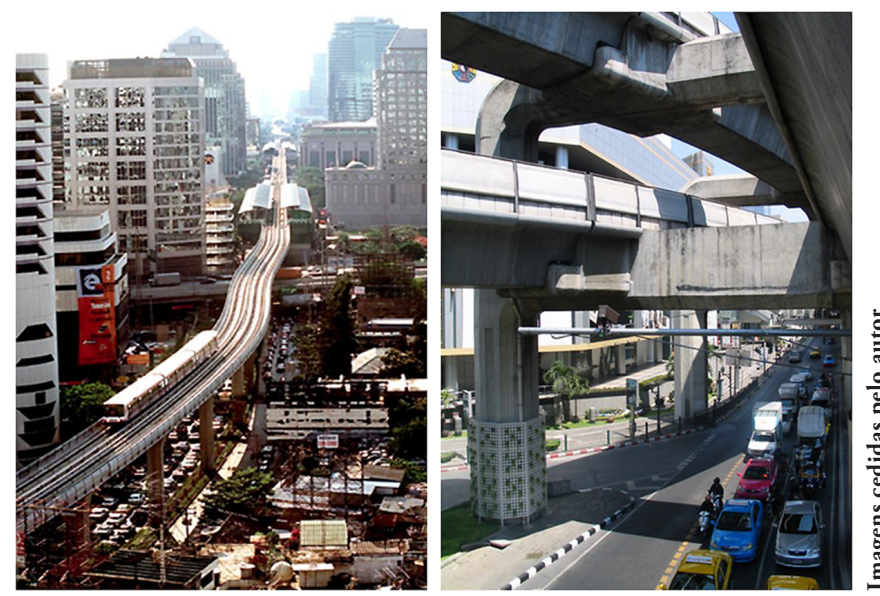

Figura 1: Ruas resultantes da construção do metrô elevado em Bangkok. construídas na época do paradigma do automóvel.

Porque a mobilidade sustentável descansa sobre a combinação de três políticas: restriçóes à circulação dos carros nas áreas centrais das cidades, melhorias no transporte coletivo e recuperação do espaço da caminhada e dos veículos não motorizados.

Pouco adianta investir muito no transporte coletivo e, ao mesmo tempo, incrementar o espaço destinado aos veículos privados, com projetos que estragam o espaço dos pedestres. Quase todos os cariocas se mostram satisfeitos com a construção dos corredores de Bus Rapid Transit (BRT), porque significam uma grande atenção ao transporte coletivo, até agora suprido por milhares de ônibus velhos, semivazios, indisciplinados, incômodos e barulhentos. E eles têm razão. Porém, cabem as seguintes perguntas: tinham que ser construídos sobre viadutos elevados que estragam as ruas que ficam abaixo? Precisavam ter novas pistas rápidas de carros no entorno das estaçóes, dificultando seu acesso?

Talvez as soluçóes implementadas sejam produtos das estratégias dos grupos empreiteiros que preferem infraestruturas elevadas, porque são incapazes de resolver os problemas do subsolo das ruas (antes desapropriar pobres do que brigar com as companhias de serviços públicos) e porque se justifica melhor o elevado custo da obra (as estaçóes com passarelas e pilares de concreto são muito mais caras do que a simples pintura de faixas de pedestres no asfalto).

Os argumentos utilizados são contraditórios: o acesso à estação se fez por passarelas para evitar acidentes com carros que circulam por vias rápidas construídas pela mesma obra, embora a tecnologia BRT, precisamente, se justifique porque a sua regularidade e o controle informático permitem abrir os semáforos de pedestres ao mesmo momento em que está chagando o ônibus, parando os carros e 


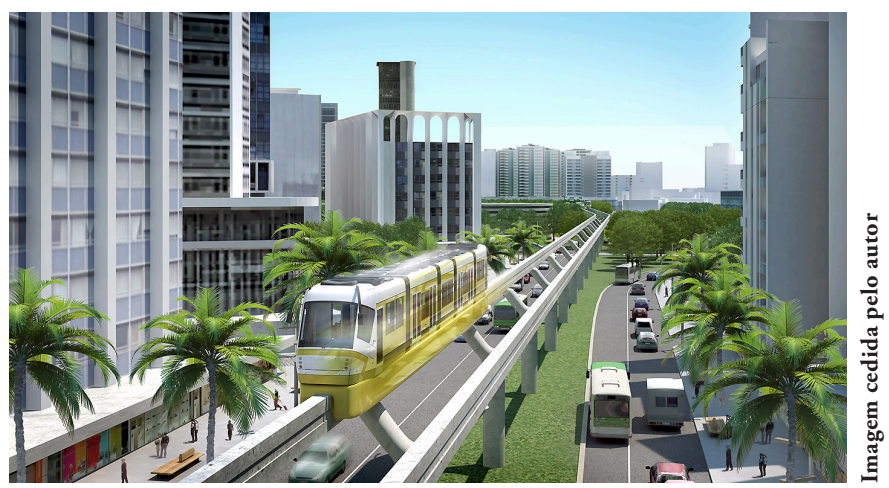

Figura 2: Proposta de "monotrilho" para uma linha de transporte coletivo em São Paulo.

diminuindo sua velocidade.

Tampouco deve-se esquecer que as maquetes e fotomontagens de obras complicadas são do gosto dos políticos, que vendem "modernidade", mesmo que não se importem com o sentido comum, do qual parecem carecer.

O projeto olímpico do Rio de Janeiro concentrou o foco principal dos Jogos no extremo sul da Barra de Tijuca, a $25 \mathrm{~km}$ do centro da cidade. $\mathrm{O}$ pretexto para essa decisão, que reforça a expansão da cidade burguesa para as praias do Sul-Oeste, era que a iniciativa privada financiaria grande parte do investimento, construindo a Vila Olímpica e financiando parte do parque olímpico.

Para apoiar a decisão, era necessária uma importante melhoria da acessibilidade dessa região que, naquele momento, descansava na congestionada autoestrada Lagoa-Barra e na autoestrada do pedágio $9 \mathrm{da}$ Linha Amarela. A solução era simples: levar até lá o metrô (em uma extensão de $12 \mathrm{~km}$ ) e construir três corredores BRT; dois deles desde o norte e centro da cidade, financiados, isso sim, pelo setor público, mesmo que tenha sido privatizada a exploração dos sistemas.

O belo discurso da aposta pelo transporte público caiu bem entre a população, mesmo que algumas vozes críticas tenham sinalizado que esse enorme investimento beneficiaria uma regiáo pouco

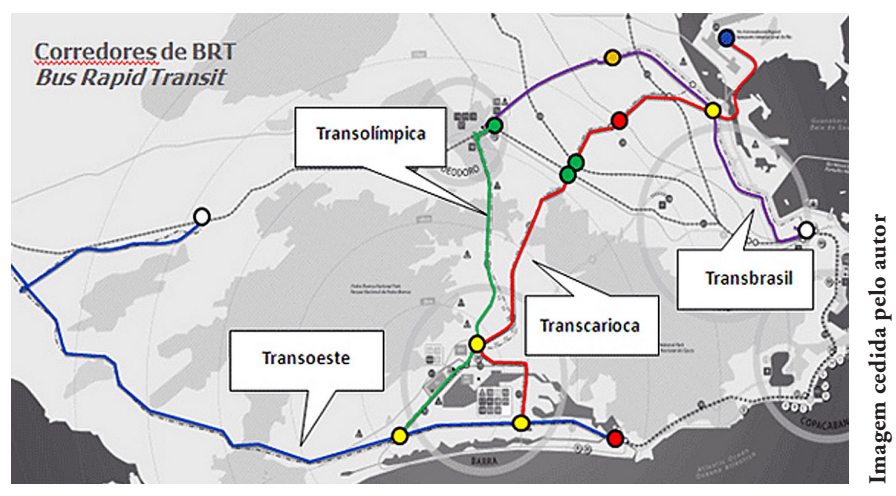

Figura 3: Corredores de Bus Rapid Transit (BRT), concebidos como legado olímpico.

povoada, retirando recursos das áreas mais ocupadas da cidade e mais necessitadas de melhorias no transporte. Para calar essa crítica, foi lançada, com grande publicidade, a reforma da área portuária (o Porto Maravilha) na cidade central, mas deixando claro que a conexão com o projeto olímpico era somente temporal.

Como o Instituto de Arquitetos denunciou tal incoerência, a prefeitura aceitou locar lá a Vila Olímpica da Mídia e apadrinhou um concurso internacional para seu desenho. O ganhador do concurso foi um arquiteto carioca associado a um time cataláo.

Pouco restou do projeto ganhador quando ele passou pelo crivo das empreiteiras concessionárias da Operação Urbana Consorciada do Porto Maravilha. O prédio não tem nada a ver com a

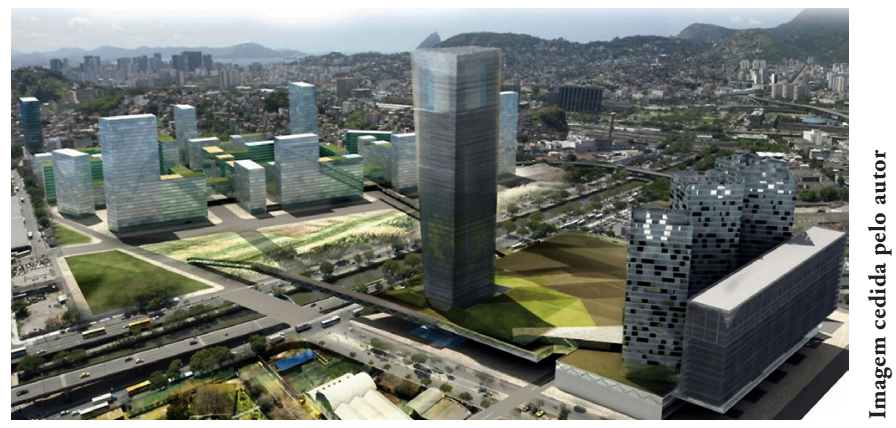

Figura 4; Proposta ganhadora do concurso de Vila Olimpica no Porto Maravilha. 


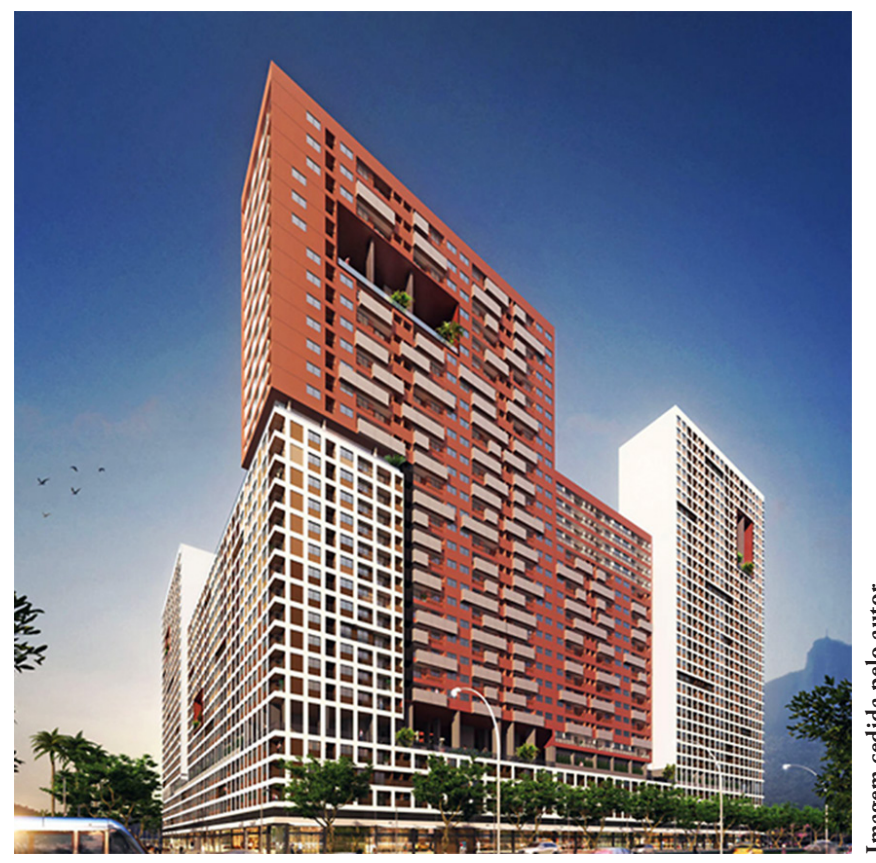

Figura 5: Projeto para Vila da Mídia em construçâo, atualmente parada.

proposta ganhadora e o abandono final da obra levou a prefeitura a tirar de lá a Vila Olímpica da Mídia.

Voltemos aos corredores BRT. A engenharia urbana significa uma maneira diferente de entender o projeto de infraestruturas dentro das cidades, onde o espaço tem características que o diferenciam - e muito - do espaço rural. No espaço urbano, os aspectos funcionais da infraestrutura têm que ser respeitados, mas devem se adequar às limitaçóes que outras funçóes urbanas estabelecem e a solução da sua implantação formal deve estar a serviço da construção de um novo tipo de espaço público. Assim, uma rua é muito mais do que um conjunto de pistas para o tráfego rodado. Uma interseção tem que ser concebida não simplesmente pela resoluçáo dos conflitos do trânsito, mas, também, como a futura praça a ser configurada. A estação é uma importante centralidade urbana a ser aproveitada na consecuçáo de uma cidade melhor.

Esses elementares princípios de desenho parecem esquecidos nos projetos dos corredores de BRT construídos no Rio de Janeiro, possivelmente porque esses projetos foram elaborados pela Secretaria de Transporte, com escassa colaboração da Secretaria de Urbanismo. Dessa maneira, os elogios às obras são mais pelo espetacular do que pela utilidade que elas poderiam ter tido na organização dos bairros que os BRT atravessam.

Não se pode defender a sustentabilidade, por exemplo, do corredor Transcarioca, que une o aeroporto com o Parque Olímpico, em um percurso de quase $40 \mathrm{~km}$. Primeiro, porque ele mal se conecta com outras linhas de transporte que diz alimentar; segundo, porque significou a desapropriaçáo de quase 3 mil moradias; e terceiro, porque no corredor desapropriado, tem sido construída uma autoestrada nova com 6 pistas de circulação expressa de carros.

Essa nova autoestrada trouxe um difícil acesso para muitas das estaçóes do próprio BRT, com passarelas de cruzamento das pistas que incomodam e atrapalham o acesso dos usuários para que os carros não precisem parar. Bela solução para a sustentabilidade!

No primeiro dos corredores construídos, o Transoeste, que transcorre pela Avenida das

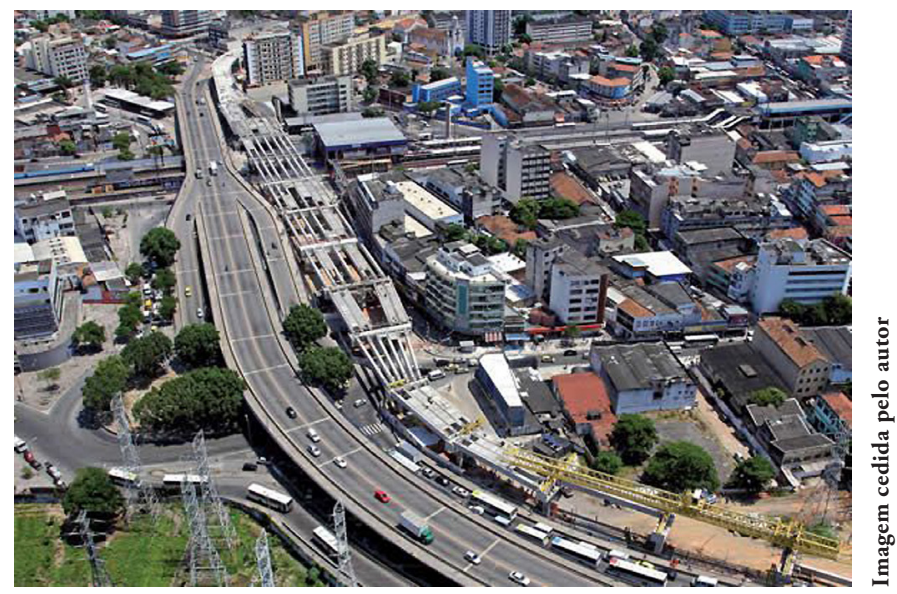

Figura 6: Seção do corredor BRT Transcarioca. 


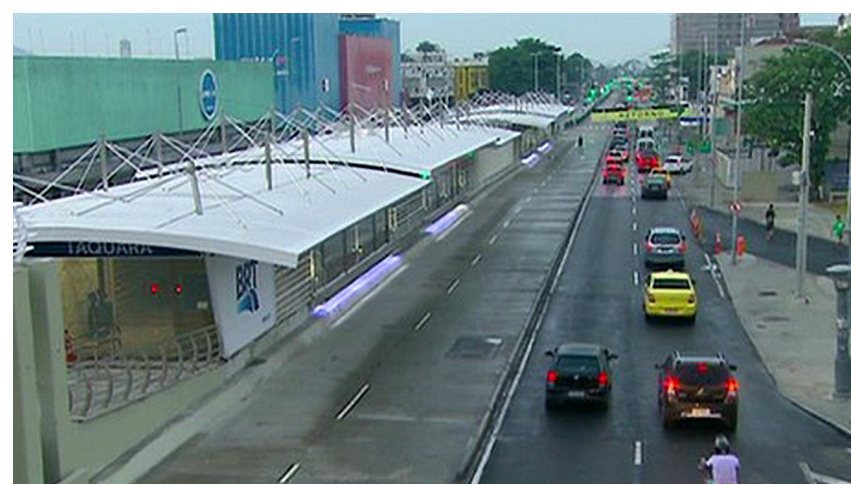

Figura 7: Estação na Transoeste e cruzamento com carros.

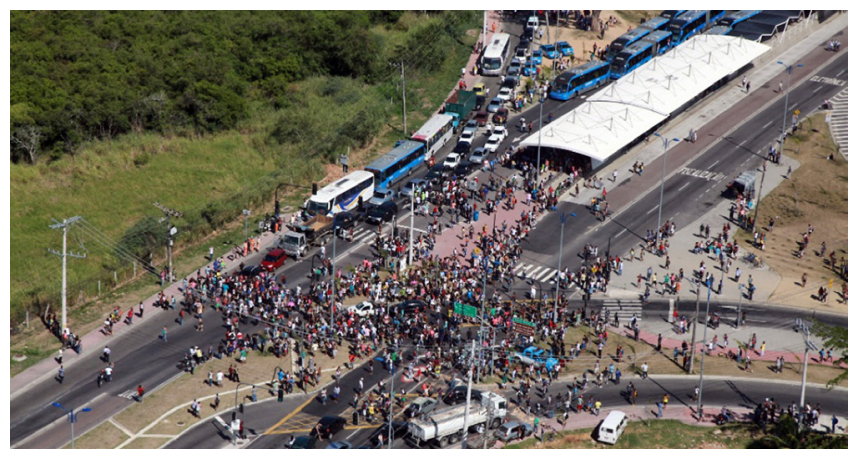

Figura 8: Protestos pelos acidentes.

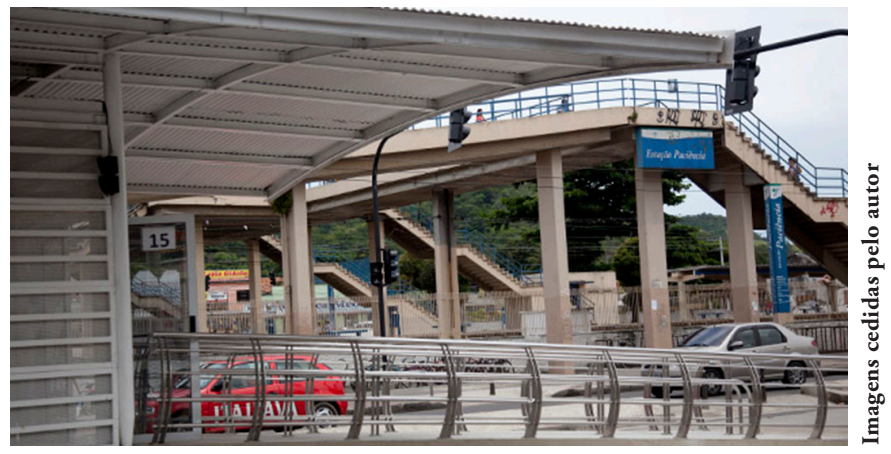

Figura 9:Passarelas para pedestres nas últimas estaçóes construidas.

Américas na Barra, a opção de acesso às estações foi a correta: no mesmo nível das pistas, com faixas de cruzamento. O problema esteve na falta de proteçáo aos acessos, sem semáforo muitas vezes e sem préaviso de parada nos carros. Os múltiplos acidentes decorrentes provocaram todo tipo de protestos, mas a "culpa" foi colocada nos pedestres, e não no sacrossanto carro, de modo que, nos outros novos corredores, começaram a aparecer soluções (por

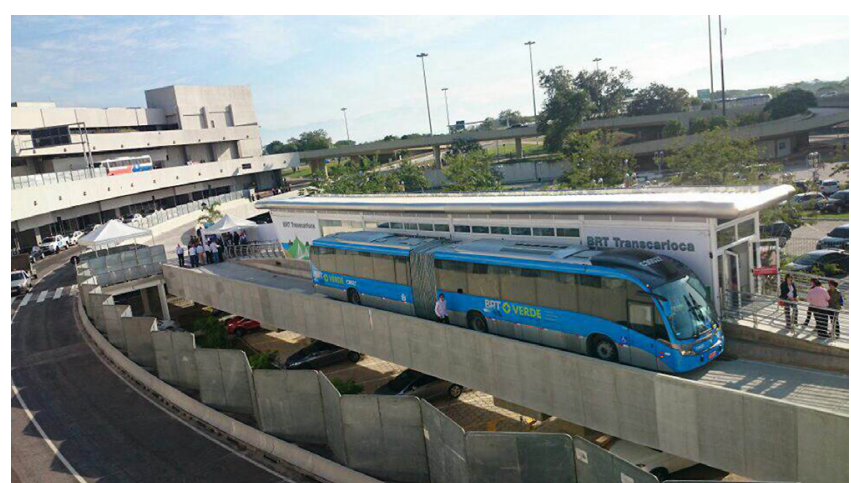

Figura 10: Estaçâo terminal do BRT Transcarioca no aeroporto, atrás das pistas de acesso de carros.

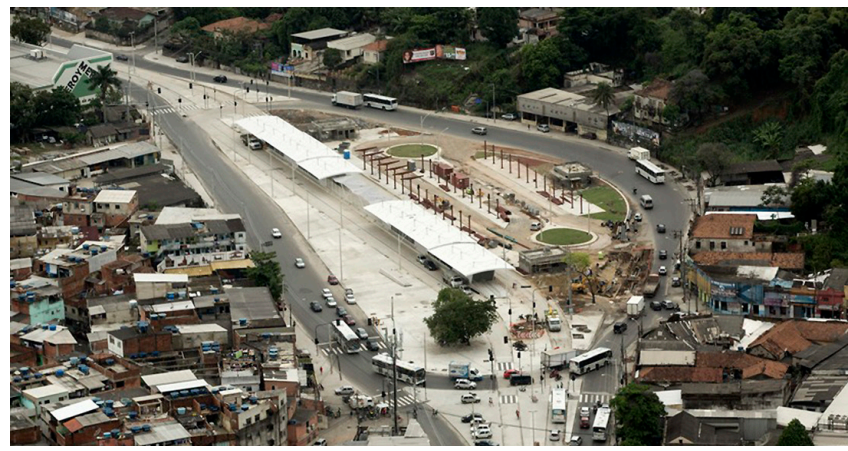

Figura 11: Estação da Transcarioca que não aproveita a ocasião de gerar uma centralidade urbana.

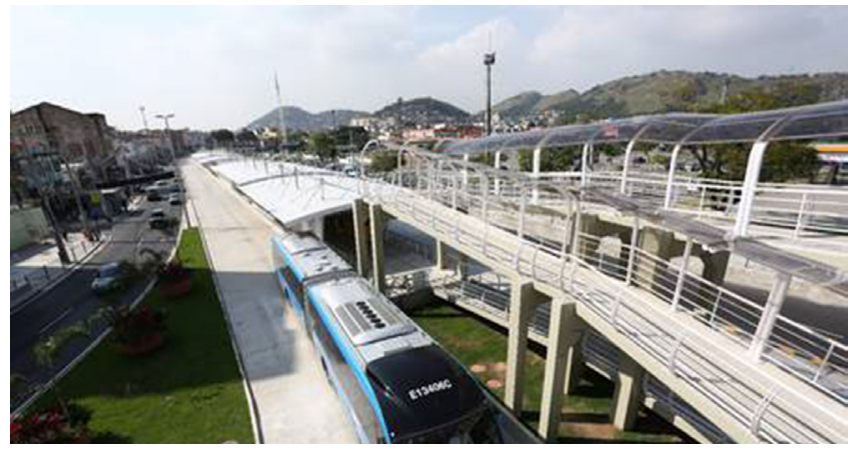

Figura 12: Acesso a uma estação do BRT na Transcarioca.

sorte não de modo generalizado) de acesso com passarelas sobre as pistas.

Essa volta a padróes calcados no paradigma de respeito ao carro e do desprezo pelo pedestre parece ter iluminado a concepção das obras do BRT Transcarioca, que liga o aeroporto com a Área Olímpica da Barra. São mostrados alguns exemplos como provas claras da oportunidade perdida de 


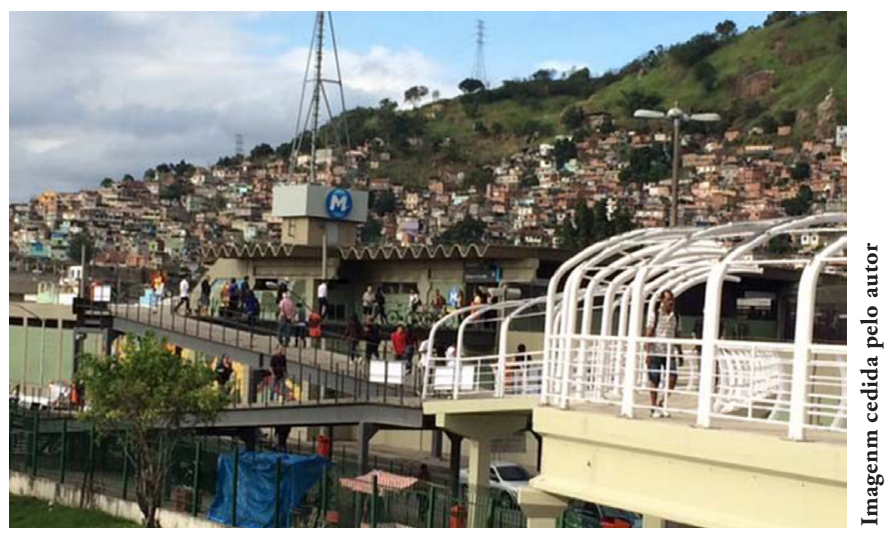

Figura 13: Integração de estaçóes do BRT e o metrô na Transcarioca.

construir praças e espaços urbanos de qualidade.

No mesmo sentido, assombra a incapacidade mostrada na resolução das transferências entre o BRT e os outros modos de transporte coletivo, quando está claro que, na rapidez e na comodidade dessa operação, reside grande parte da eficácia de um sistema integrado de transporte. E não é apenas isso: as cidades mais desenvolvidas estão aproveitando a grande quantidade de passageiros que por lá passam diariamente para estruturar, sobre esses espaços, políticas de requalificação urbana. Mostram-se, também, algumas imagens da maneira como se vem resolvendo esses intercâmbios: passarelas, desníveis, percursos absurdos e áreas destinadas a cada modo de transporte distantes e dissociadas entre elas.

Seria quase cruel comparar essas soluçóes com análogas realizaçóes europeias, como, por exemplo, as estaçóes do Ave espanhol ou francês e suas conexôes com metrô e ônibus, organizadas com diferentes níveis e transbordos verticais. Mas, de todas as maneiras, os urbanistas cultos cariocas sabem bem que as soluçóes adotadas pertencem a um passado já superado nas cidades ocidentais. $\mathrm{O}$ problema é que eles não foram consultados.

\section{A reforma das Avenidas Brasil e Francisco Bicalho e o BRT Transbrasil}

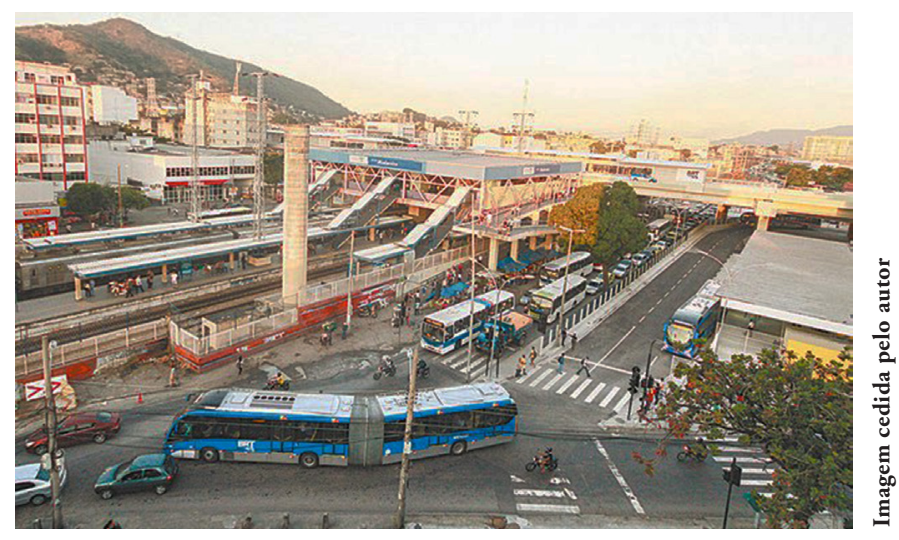

Figura 14: Estaçâo de conexão BRT - Supervia ferroviária no BRT Transbrasil.

O projeto do BRT Transbrasil, que circula na Avenida Brasil desde Deodoro ao Centro, merece um comentário específico.

Esse comentário vai permitir comparar a visão das obras atuais com o abortado projeto de transformação da Avenida do Prefeito Luís Paulo Conde, que contratou, em 1997, um time constituído pelo engenheiro José Franklin, o arquiteto Tiago Holztman e o engenheiro autor deste artigo. A preocupaçáo fundamental do encargo do prefeito era aproveitar o investimento para três finalidades:

$1^{\text {a }}$ - Dotar urbanidade a uma autoestrada que organiza e atravessa os bairros da Zona Norte da cidade, introduzindo nela calçadas, praças e arborização.

$2^{\mathrm{a}}$ - Ordenar o tráfego rodado, diferenciando pistas centrais, destinadas ao tráfego de acesso ao Centro, das pistas laterais, que passariam a ser ruas dos bairros, com os ônibus nelas trafegando, para aproximá-las dos bairros aos quais servem.

$3^{\mathrm{a}}$ - Destinar uma parte do investimento à geração de praças identificadoras de cada bairro, lugares onde concentrar as paradas de transporte público e as passarelas de cruzamento da Avenida (melhorando as já existentes).

Nas imagens a seguir, mostra-se a solução proposta 


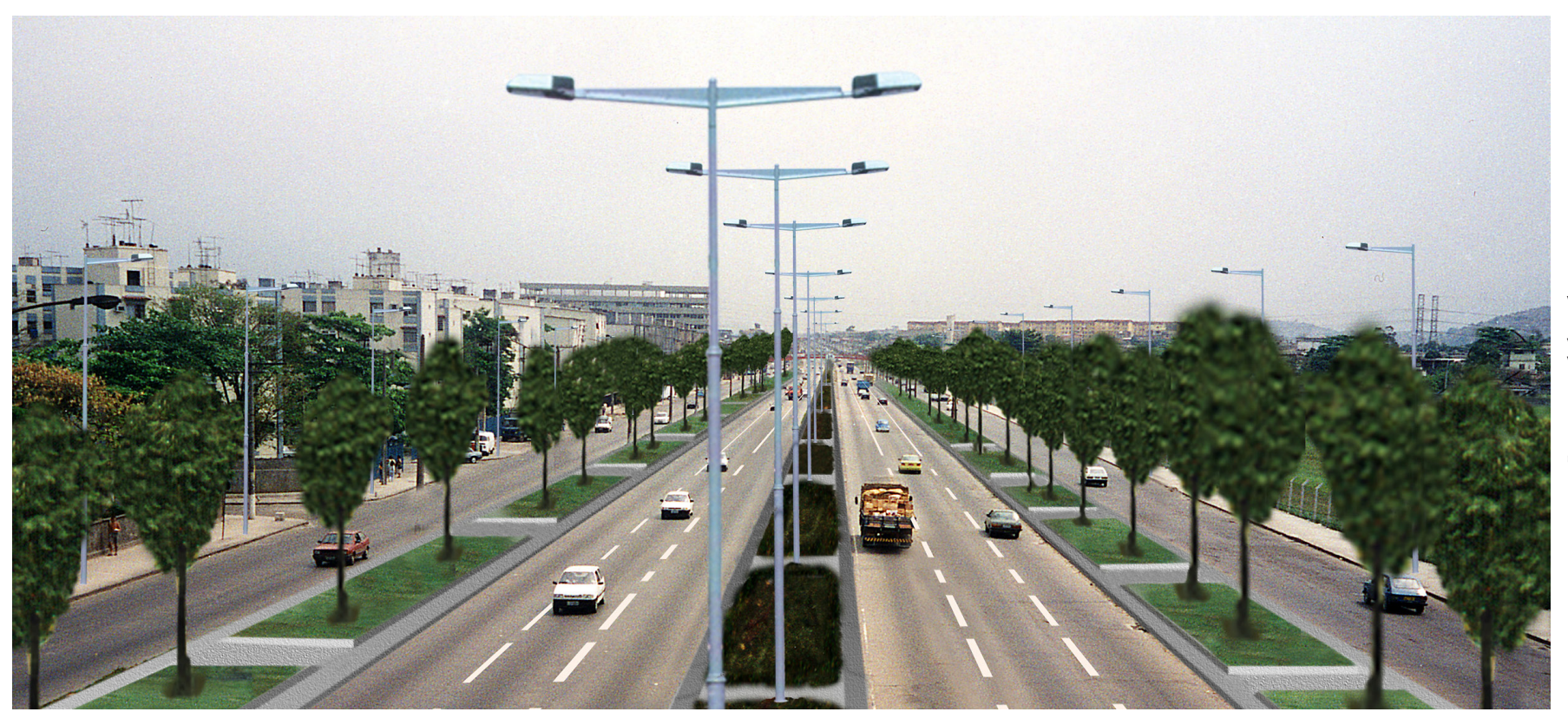

Figura 15: Seção da proposta no projeto de reforma da Avenida Brasil de 1997.

para a reforma da Avenida, na qual se destinavam $13 \mathrm{~m}$ em cada sentido para pistas expressas nas faixas centrais e $9 \mathrm{~m}$ nas ruas laterais com calçadas de largura variável, no mínimo de $2,5 \mathrm{~m}$. Tudo isso dentro da faixa existente na atualidade.

$\mathrm{O}$ aspecto mais marcante do projeto foi a decisão da ordenação de praças (uma dúzia) nos espaços de acesso a cada bairro, coincidentes com as passarelas existentes (a serem remodeladas) e as paradas de ônibus. Todas essas praças procuravam a mesma imagem, embora a sua forma e seu tamanho dependessem do espaço existente.

O pavimento escolhido para as calçadas das ruas foi o paralelepípedo vermelho, cortado por sarjetas perpendiculares ao meio fio (coincidentes com as copas das árvores a serem plantadas), segundo o modelo mostrado na figura 16.

A decisão de diferenciar o espaço da praça foi a de utilizar pedra portuguesa de três cores, com idênticas figuras desenvolvidas desde o canto da praça, segundo se mostra na imagem, com a intenção de mostrar aos passageiros a sua chegada no espaço central do bairro, levando em

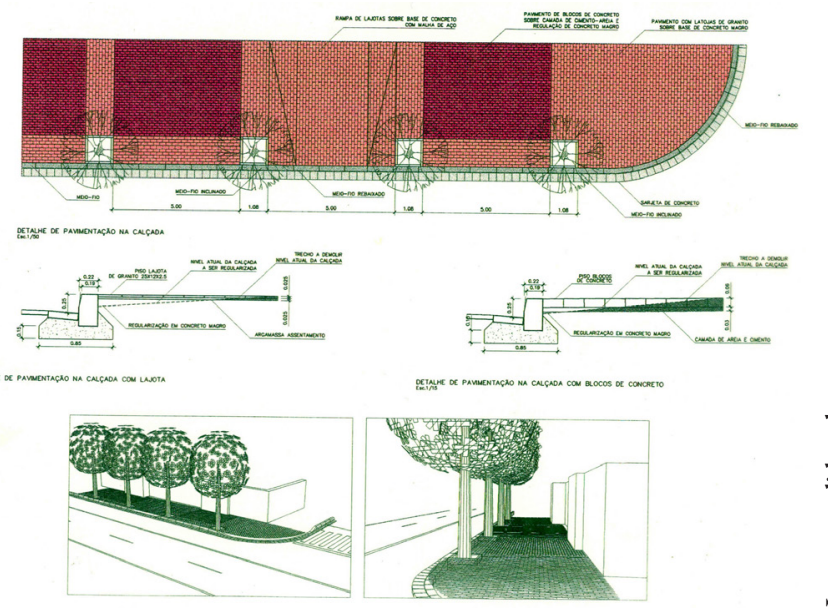

Figura 16: Proposta de ordenação de calçadas.

consideração que a pedra portuguesa é o material das praças "nobres" da cidade.

As futuras praças estariam, assim, constituídas por quatro elementos comuns identificadores: pavimento diferente do resto das calçadas, passarelas com o nome do bairro, baias para paradas de ônibus nas bases das passarelas e abrigos uniformizados com elementos identificadores do bairro, conforme a imagem 18 . 

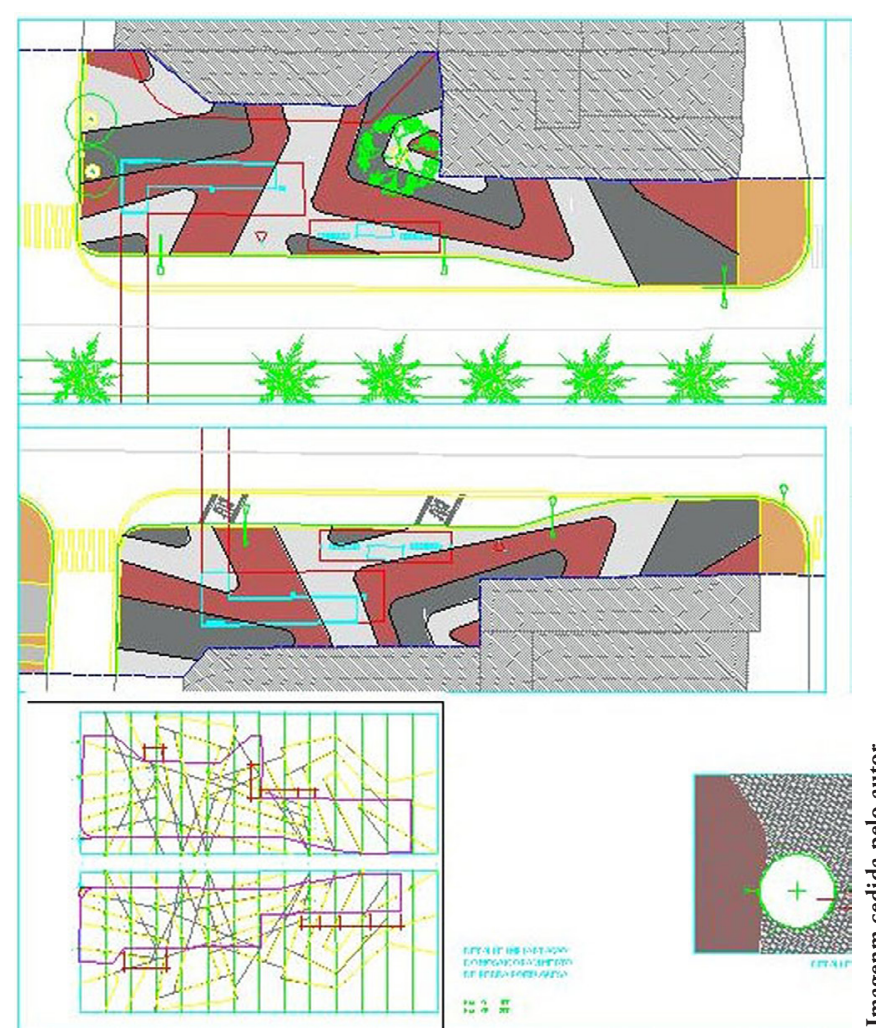

Figura 17: Conformação do pavimento das praças.
O projeto foi muito cuidadoso com o custo das obras, sendo o das praças aproximadamente $5 \%$ do total. Só foram executadas obras de calçadas em um trecho de $300 \mathrm{~m}$ no Caju, e plantadas quase 2000 palmeiras nos canteiros separadores de praças e ruas; com a mudança na administraçáo municipal, as obras pararam. Não é objetivo deste texto falar de mais um dos projetos abortados na história da cidade, mas sim, comparar o cuidado tido em aproveitar o investimento, melhorando o espaço urbano dos bairros com a estratégia de simplesmente passar um corredor de transporte coletivo BRT. São mostradas a seguir algumas imagens das obras para reforçar a argumentação.

Entretanto, o aspecto mais irritante que mostra um tal desprezo pela cidade e que deveria ter arrancado protestos indignados não só dos profissionais, mas de todos que amam a cidade, é a proposta de acabar para sempre com o Canal do Mangue no trecho que já foi símbolo do poder da República
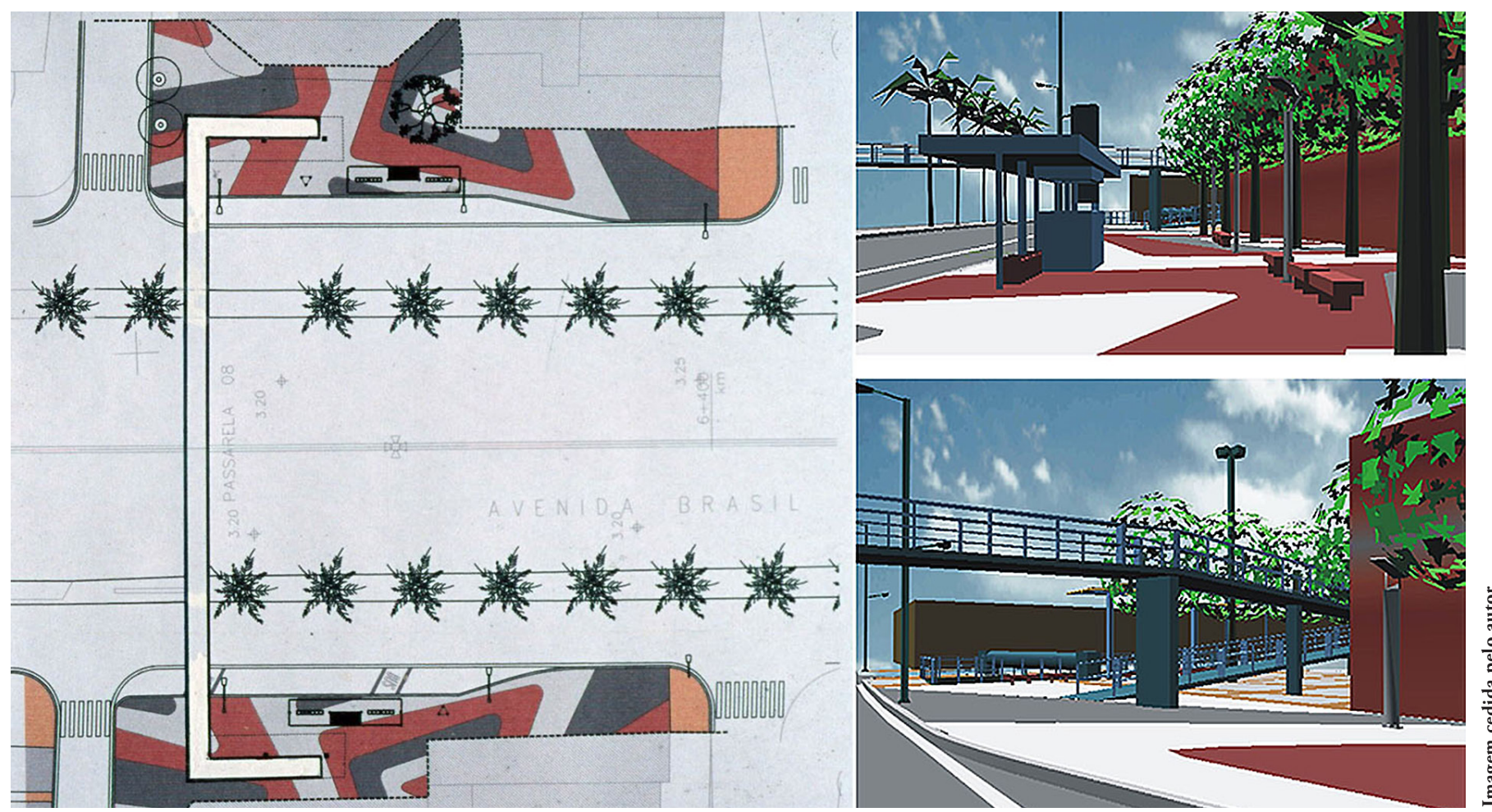

Figura 18: Ordenação proposta para as praças.

Revista online do Departamento de Arquitetura e Urbanismo da Pontifícia Universidade Católica -

Puc-Rio - Rio de Janeiro Brasil

Ano III - N III - ISSN 2446-7340 


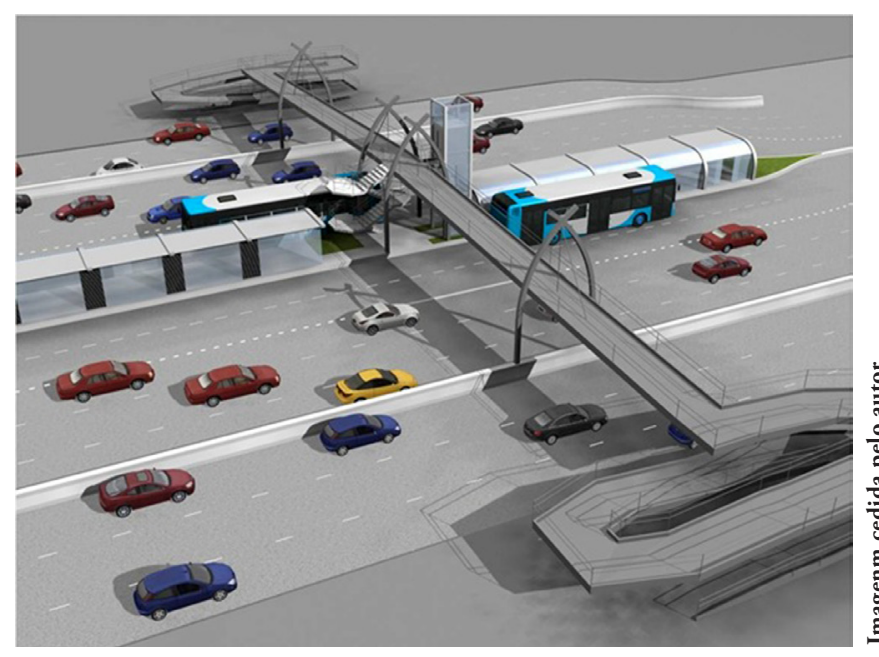

Figura 19: Proposta de ordenação das estaçôes.

na construção da sua moderna capital, na nobre e, hoje, deteriorada Avenida Francisco Bicalho.

O discurso do Porto Maravilha apoiou a recuperação da Avenida e do Canal, lembrando que os piscinóes da Praça da Bandeira foram construídos para acabar com as enchentes e para a limpeza do canal.

Assim, o projeto de obras do BRT optou por instalar as estaçóes sobre o próprio canal, enterrando-o parcialmente.

E, inclusive, com passarelas de acesso sobre as pistas laterais, para não atrapalhar o tráfego (parado já pelos engarrafamentos) da Avenida. Quem recorda como o canal já foi?

Poderiam ser feitas ainda muitas outras consideraçóes sobre a ausência de projeto de espaço público nas obras olímpicas e sobre o erro de uma política de mobilidade que só atende ao transporte coletivo sem tocar no carro, esquecendo dos pedestres. Creio que o que foi aqui comentado tenha sido o suficiente para suscitar um debate necessário sobre o futuro da cidade, que já fora iniciado por alguns destacados urbanistas cariocas. Enquanto isso, a sociedade civil fica desconcertada perante o discurso oficial de realizaçôes, obras

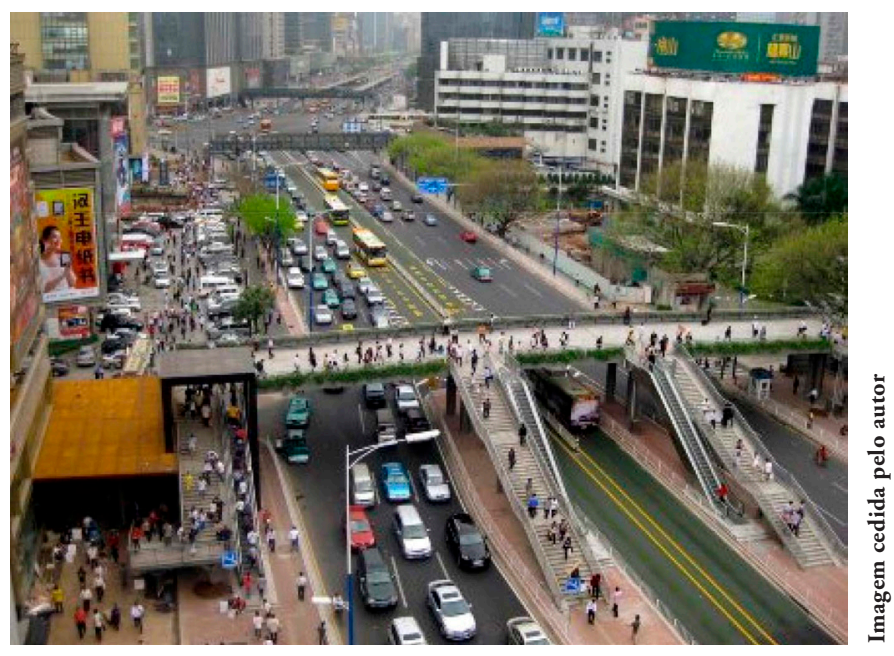

Figura 20: Obras de construção de espaço público. Quais as melhorias? Qual o legado?

e legados de uma realidade da qual sempre desconfiou.

Mas por que temos que ser diferentes dos outros países? A nossa tradição cultural exige críticas mais acirradas e menos "panos quentes". Estamos falando do nosso espaço, do espaço público da nossa cidade.

As Olimpíadas foram um grande momento, porém, depois da "farra", o que restou? Não basta falar que se seguiu o modelo Barcelona, Seul ou Londres, porque isso não é verdade. Vejo mais o reflexo do modelo de Atlanta ou de Atenas, lembrando de dois eventos que também não devem ser esquecidos.

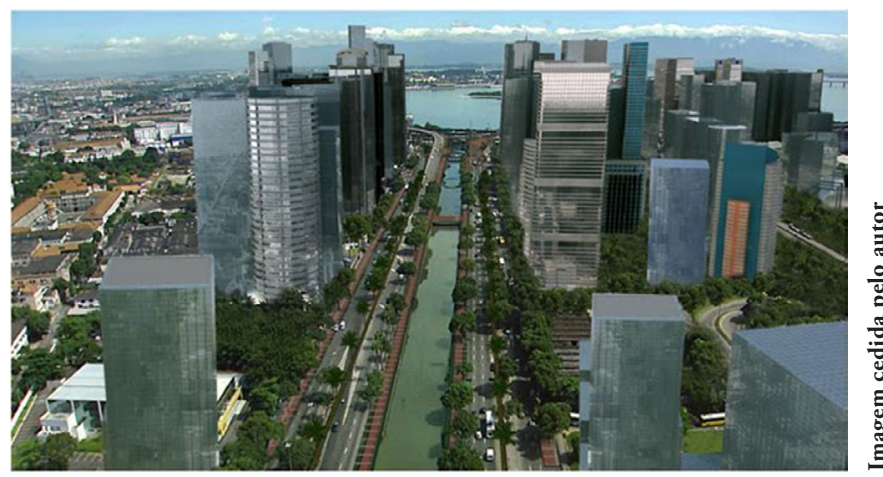

Figura 21: Recuperação da Avenida Francisco Bicalho, segundo a Empresa Olímpica. 


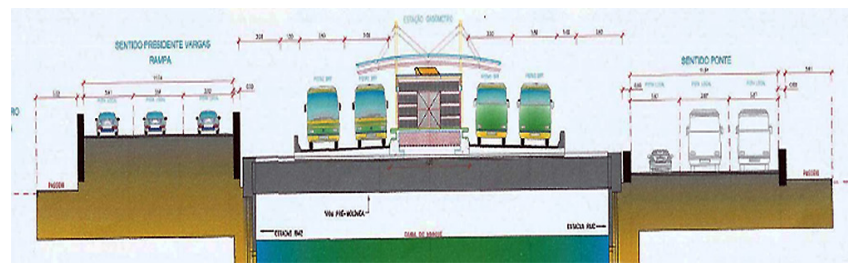

Figura 22: Proposta de estaçóes no canal da Avenida Francisco Bicalho.

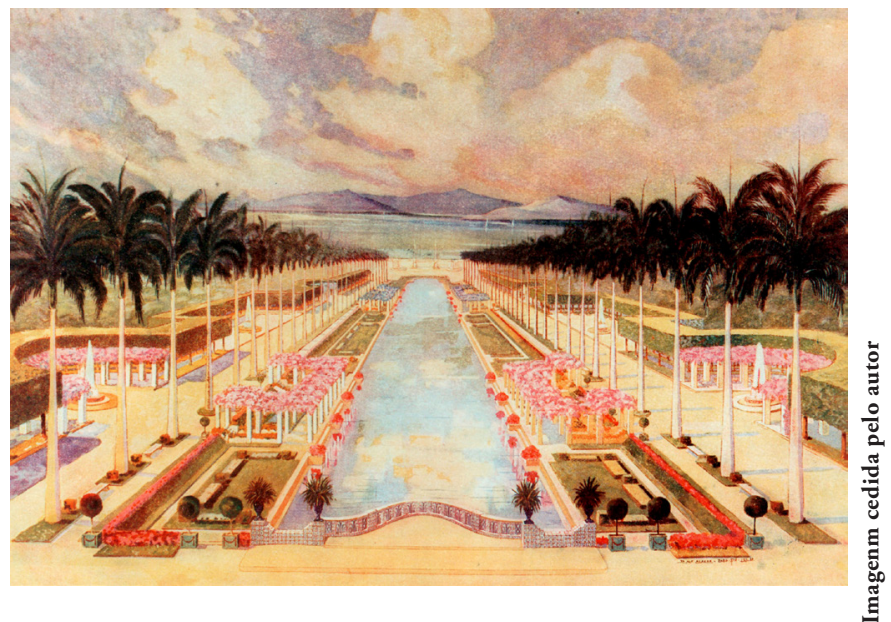

Figura 23: O projeto de construção do canal pela República Constituinte.

\section{Referências bibliográficas}

BROTO, Carlos. Arquitectura para el transporte.

Barcelona: Ed. Links, 2012.

HERCE, Manuel. Sobre la movilidad en la ciudad. Barcelona: Ed. Reverté, 2009.

HERCE, Manuel. El espacio de la movilidad urbana. Buenos Aires: Ed. Cafedelasiudades, 2013.

HERCE, Manuel. O negócio da cidade. Rio de Janeiro: Ed. Mauad, 2015.

MAGALHÁES, Sergio; JANOT, Fernando. Diversos artigos no jornal O GLOBO.

SOCIEDAD CENTRAL DE ARQUITECTOS. Brasil, utopias y realidades. Revista de Arquitectura n. 255, 2015. 